\title{
Stochastic rainfall analysis for storm tank performance evaluation
}

\author{
I. Andrés-Doménech ${ }^{1}$, A. Montanari ${ }^{2}$, and J. B. Marco ${ }^{1}$ \\ ${ }^{1}$ Instituto de Ingeniería del Agua y Medio Ambiente, Universidad Politécnica de Valencia, Camino de Vera s/n, \\ 46022, Valencia, Spain \\ ${ }^{2}$ Facoltà di Ingegneria, Università di Bologna, Viale Risorgimento 2, 40136 Bologna, Italia
}

Received: 4 February 2010 - Published in Hydrol. Earth Syst. Sci. Discuss.: 11 March 2010

Revised: 21 June 2010 - Accepted: 1 July 2010 - Published: 9 July 2010

\begin{abstract}
Stormwater detention tanks are widely used for mitigating impacts of combined sewer overflows (CSO) from urban catchments into receiving water bodies. The optimal size of detention tanks depends on climate and sewer system behaviours and can be estimated by using derived distribution approaches. They are based on using a stochastic model to fit the statistical pattern of observed rainfall records and a urban hydrology model to transform rainfall in sewer discharge. A key issue is the identification of the optimal structure of the stochastic rainfall model. Point processes are frequently applied, where rainfall events are schematised through the occurrence of rectangular pulses, which are governed by rainfall descriptors. In the presented model these latter descriptors are the interevent time (duration of the dry period between consecutive storms), event rainfall depth and event rainfall duration. This paper focuses on the analytical derivation of the probability distribution of the number and volume of overflows from the storm tank to the receiving water body for different and non-standard shapes of the probability distribution for above mentioned descriptors. The proposed approach is applied to 2 different sites in Spain: Valencia and Santander, located on the Mediterranean and northern Atlantic coastline, respectively. For both cases, it turned out that Pareto and Gamma-2 probability distributions for rainfall depth and duration provided a better fit than the exponential model, widely used in previous studies. A comparison between the two climatic zones, humid and semiarid, respectively, proves the key role played by climatic conditions for storm detention tanks sizing.
\end{abstract}

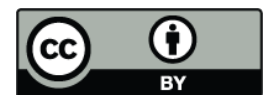

Correspondence to: I. Andrés-Doménech (igando@hma.upv.es)

\section{Introduction}

Stormwater detention tanks are widely used for mitigating impacts of combined sewer overflows into receiving water bodies. Even if a lot of methodologies for sizing these facilities have been developed in the last decades, there are still some open questions for the determination of the appropriate detention volume required to keep the overflow pollutant concentration within acceptable limits (Deutsch et al., 2003). Some countries are making strong efforts to standardize these methods, always realizing that climatic conditions play a key role (Woods-Ballard et al., 2007). In general, techniques used to size such storage facilities and analyze their performance fall into two categories: analytical methods and simulation approaches. Analytical statistical methods estimate tank performances by analytically deriving the probability distribution of tank failure and overflow volume, depending on rainfall statistics and by using simple schemes to compute the sewer flow. Simulation approaches are carried out by generating synthetic long series of sewer discharges, from which statistics for tank performance can be derived. Analytical methods have the advantage of being simple and allow to quickly screen a wide range of design possibilities. Conversely, simulation procedures are time consuming. They can be used to refine the solution by exploring with more details few final alternatives. In this paper we focus on the former category, therefore estimating tank efficiency by means of analytical derivation, while we validate the results by performing continuous simulation.

Since DiToro and Small (1979) developed one of the first probabilistic methods the state-of-the-art has notoriously improved. Early developments by the US Environmental Protection Agency (EPA) (Driscoll et al., 1986) described the probability density function of the runoff process and their relationship with tank performance. Later, some quality aspects such as pollutant removal by sedimentation were considered (Walker et al., 1993; Papa and Adams, 1996).

Published by Copernicus Publications on behalf of the European Geosciences Union. 
All probabilistic approaches require a description of the rainfall input through a stochastic model. Point processes are frequently applied where rainfall events are schematised through the occurrence of rectangular pulses, which are governed by rainfall descriptors. In the presented model these latter are the expected values of (1) interevent time, (2) event rainfall depth and (3) event rainfall duration. A key issue is the description with probability density functions (pdfs) of the frequency of occurrence for the above descriptors. Exponential functions have been usually adopted. In fact, most of the models used to date are based on this assumption (DiToro and Small, 1979; Adams et al., 1986; Guo and Adams, 1999; Guo and Urbonas, 2002). Actually, robust probabilistic methods, developed in the US and Canada, use the above assumption. One of the reasons why the exponential probability distribution has been widely used is its simplicity, which makes analytical derivation easier. On the other hand, it has limited ability to describe rainfall statistics in some cases, including the rainfall series analysed in this paper. Therefore we looked for an alternative approach.

In this paper an analytical model for designing the storage volume of detention tanks is proposed, which uses alternative solutions to the exponential distribution for rainfall descriptors. A simple conceptual rainfall-runoff model is used to transform rainfall into sewer discharge, therefore allowing to analytically deriving the probability distribution of number and volume of overflows for the detention tank.

The suitability of the exponential model for rainfall descriptors is first discussed with reference to the rainfall series of two different sites in Spain: Valencia and Santander. As significant differences from the exponential model emerge, alternative probability distributions are considered. Subsequently, results for rainfall characterisation in northern and Eastern Spain are compared. Finally, analytical probabilistic expressions are derived in order to assess the frequency of occurrence of number and volume of tank overflows, allowing to estimate the storm tank efficiency. In detail we estimate volumetric efficiency and overflow reduction efficiency. The former is defined as the long term ratio between runoff volume produced in the urban catchment and volume detained by the tank. The latter is defined as the probability of an event to produce overflow, which can be estimated as the long term ratio of the number of events completely detained over total number of events. The accuracy of the results achieved with this latter analytical approach is checked by comparison with the outcome of a continuous simulation performed in a urban catchment in Valencia.

\section{Description of data set and case study}

\subsection{Meteorological data}

High resolution rainfall data over an extended period are needed in order to reliably assess the suitability of different probability distributions for the rainfall descriptors. Accordingly, rainfall series from Valencia (Eastern Spain) and Santander (Northern Spain) have been collected.

Valencia is located on the eastern Mediterranean coastline of Spain. Its climate is Mediterranean, mild, with some semiarid features. Average temperature is around $18^{\circ} \mathrm{C}$, with oscillations between $11^{\circ} \mathrm{C}$ in January and $26^{\circ} \mathrm{C}$ in August. Average annual rainfall depth is close to $450 \mathrm{~mm}$, with a very strong seasonality. Rainfall storms are usually concentrated in autumn, with typical very high peak intensities (torrential rain). The rainfall series was observed by the Júcar river basin hydrological service (SAIH) during the period 19902006 with 5-min resolution. Observations were checked and validated by a comparison with the Spanish Meteorological Agency (AEMET) daily observations.

Santander is located on the northern Atlantic coast of Spain. The city is under the influence of a humid oceanic climate; its main features are a mild and warm temperature regime and plenty of rainfall well distributed throughout the year. Thus, average temperatures are between $9{ }^{\circ} \mathrm{C}$ in February and $20^{\circ} \mathrm{C}$ in August and average annual rainfall depth is over $1100 \mathrm{~mm}$. The rainfall series was observed by AEMET with 5-min resolution during the period 1942-1951 and 1955-1983.

To further confirm reliability of the data, rainfall observations were aggregated into monthly and annual totals and then compared with those obtained at nearby raingauge stations. In the case of Santander the validation was fully satisfactory and, in the case of Valencia, it allowed us to identify and correct two observation errors occurred during the years 1990 and 2000. Monthly aggregated rainfall series for both locations are shown in Fig. 1.

\subsection{Case study}

The analytical model developed in this paper was applied to size and verify a detention tank located in an urban catchment in Valencia. The results are compared with those obtained with a continuous simulation approach. Environmental impacts of CSO to the receiving water bodies (Valencia beaches and the America's Cup leisure docks) are being increasingly taken into consideration. For this reason the local sewerage master plan is in charge of developing guidelines to design detention tanks.

The Pio XII urban catchment is located at the headwaters of one of the most important trunk sewers of the city, which frequently overflows into the above referred docks. The catchment is 68.8 ha large and the length of the considered 
VALENCIA

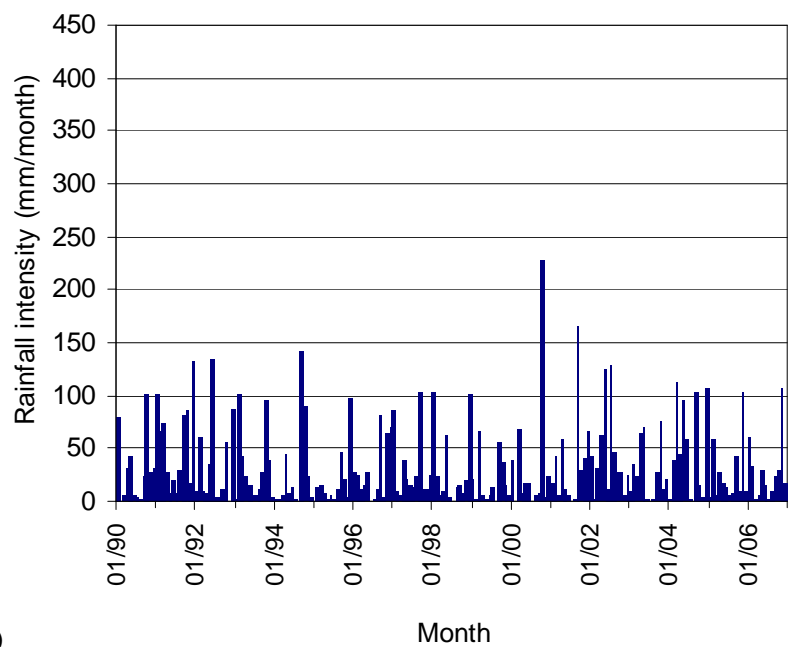

(a)

Fig. 1. Monthly rainfall time series for Valencia and Santander.

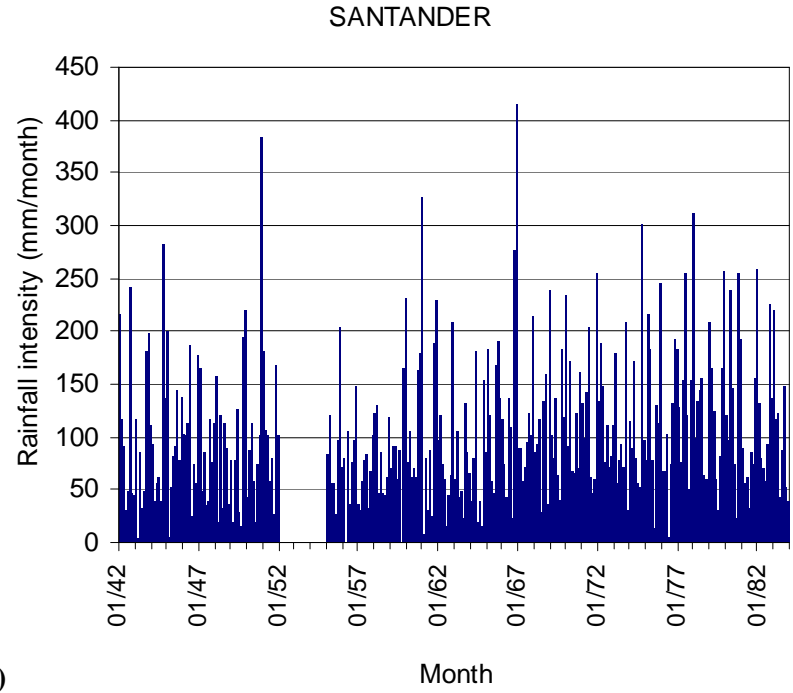

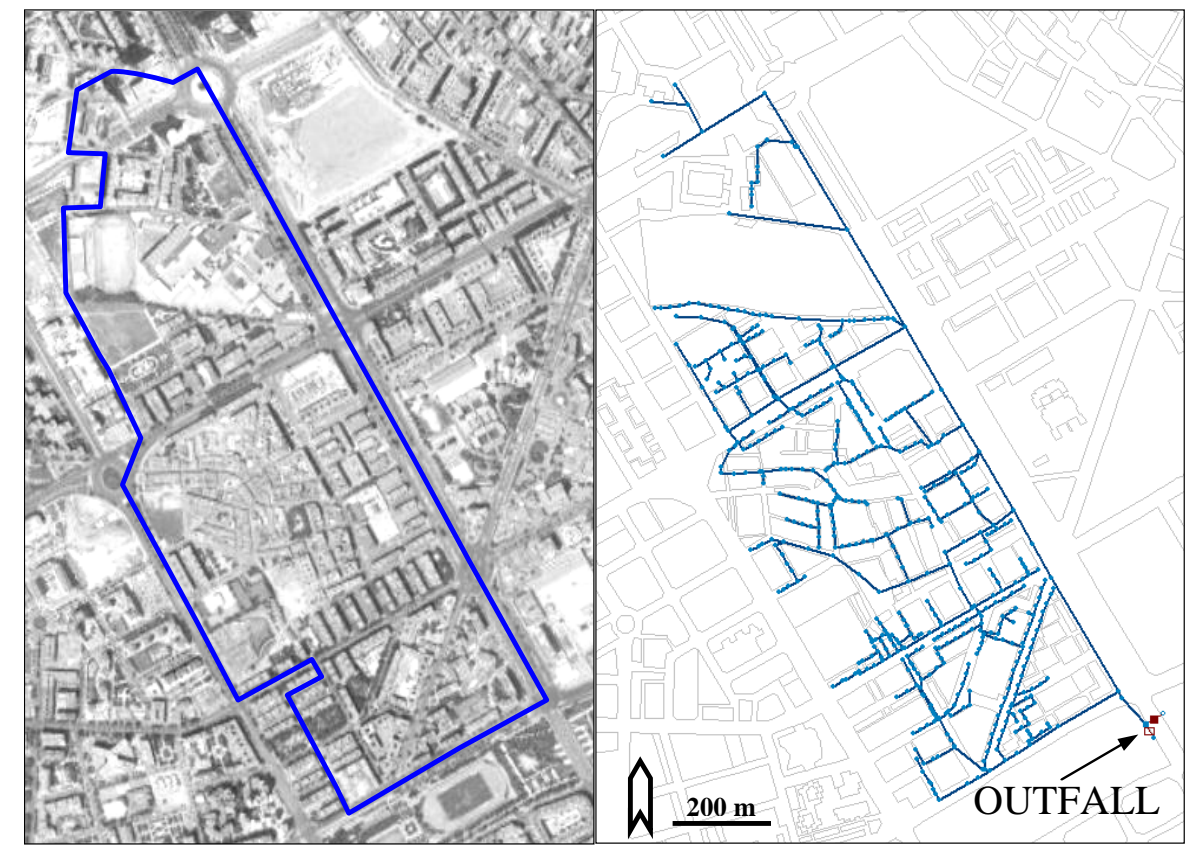

Fig. 2. The Pio XII urban catchment in Valencia: tributary area and topology.

sewer network is $13.4 \mathrm{~km}$, with 565 manholes, i.e, one manhole each $23.7 \mathrm{~m}$ on average (see Fig. 2).

The network topology and geometry, as well as historical hydraulic data, are provided by the Municipality of Valencia. Land use distribution, which is needed in order to estimate infiltration parameters for the rainfall-runoff model, is obtained from data provided by the Urban Master Plan and reclassified according to the local guidelines for sewer system design (Municipality of Valencia, 2004), which considers 4 land use types only: paved areas, high density building areas, low density building areas and green spaces. For each land use, a dimensionless area ratio, $a_{i}$, is defined as

$a_{i}=\frac{A_{i}}{A}$

where $A$ is the total tributary area of the catchment and $A_{i}$ the total area of land use $i$ in the catchment. In addition, each land use is characterized by an infiltration parameter $P_{0 i}$ 
Table 1. Pio XII urban catchment parameters.

\begin{tabular}{llccc}
\hline $\mathrm{i}$ & Area description & $\mathrm{A}_{i}(\mathrm{ha})$ & $\mathrm{a}_{i}$ & $\mathrm{P}_{0 i}(\mathrm{~mm})$ \\
\hline 1 & Paved areas & 26.73 & 0.388 & 1.0 \\
2 & High density buildings & 20.92 & 0.304 & 4.4 \\
3 & Low density buildings & 13.16 & 0.191 & 17.8 \\
4 & Green spaces & 8.01 & 0.116 & 70.2 \\
& Total & 68.82 & & \\
\hline
\end{tabular}

$(\mathrm{mm})$, which represents the runoff threshold, i.e. the amount of rainfall needed for runoff to begin. Table 1 summarizes all these parameters.

\section{Framework of the analysis}

\subsection{Rainfall model}

Rainfall characterisation is carried out by identifying and calibrating a suitable stochastic process for rainfall intensity along time. We consider a point process as a candidate model and assume rainfall events can be represented as rectangular pulses occurring accordingly to a Poisson process. This means that interevent time is exponentially distributed (Cox and Isham, 1980). We also assume that event rainfall depth and duration are outcomes from two different and independent stochastic processes. Therefore the rainfall descriptors are interevent time, $s(t)$, event rainfall depth, $v(t)$, and event duration, $d(t)$. These are supposed to be governed by stochastic processes indicated with the symbols $S, V$ and $D$, respectively.

Main steps for identification and calibration of the above rainfall model are (1) identification of statistically independent storms, (2) study of temporal dependence and cross dependence between rainfall descriptors which are derived for each event and, finally, (3) fitting of probability density functions (pdfs) to the descriptors themselves. As for step (1), the approach that is adopted here consists of selecting a critical value $s_{\text {crit }}$ for the interevent time $s(t)$, so that events separated by a dry period greater than $s_{\text {crit }}$ are considered to be independent (note that the interarrival time between events is also used with the same purpose. For a discussion see Bonta and Rao, 1988). A technique that is frequently used for selection of the optimal value of $s_{\text {crit }}$ was proposed by RestrepoPosada and Eagleson (1982). Accordingly, all events are first considered to be statistically independent therefore obtaining a sample of $s(t)$ values. Then, $s_{\text {crit }}$ is identified so that the hypothesis that the $s(t)$ values greater than $s_{\text {crit }}$ can be considered outcomes from the exponentially distributed stochastic process $S$ cannot be rejected (see also Bonta and Rao, 1988). The obtained value of $s_{\text {crit }}$ is used for identifying independent storms.
The original methodology as developed by RestrepoPosada and Eagleson (1982) establishes the selection of $s_{\text {crit }}$ by considering that the coefficient of variation $(\mathrm{CV})$ of the exponentially distributed interevent times should be equal to unity. In the operational practice, for a trial value of $s_{\text {crit }}$, statistical tests can be applied in order not to reject the hypothesis that $\mathrm{CV}=1$ for an assigned confidence level.

In the present study we developed a modified statistical criteria for the selection of $s_{\text {crit }}$. In fact, we fitted to each realisation of $S$ resulting from the corresponding trial $s_{\text {crit }}$ value a bounded exponential distribution in order to take into account that the $S$ series is limited from below by $s_{\text {crit }}$. The bounded exponential distribution is given by

$F_{S}(s)=1-e^{-\beta\left(s-s_{\text {crit }}\right)} \quad s \geq s_{\text {crit }}$.

Note that the $\mathrm{CV}$ of the bounded exponential distribution is different from unity. Then, we applied the KolmogorovSmirnov (KS) test (as done by Koutsoyiannis and Xanthopoulos, 1990) to compare the empirical and theoretical probability distribution given by (2), by using modified test statistics for the exponential model (Law and Kelton, 1991). Subsequently, we estimated the parameter $\beta$ by maximum likelihood and theoretical probabilities for each $s$ were obtained by Eq. (2). The goodness of fit was also checked by computing the Nash-Sutcliffe (NS) index of the empirical versus the theoretical distributions and the progress of the mean value of $S$ and the average number of events per year against $s_{\text {crit }}$, which should follow a linear relationship for a Poisson process (see Sect. 4.1). If a reasonable value for $s_{\text {crit }}$ can be estimated, suitability of the exponential distribution for interevent time is confirmed, therefore providing support to the assumption that rainfall events occur according to a Poisson process.

Once $s_{\text {crit }}$ is selected, $v(t)$ and $d(t)$ values can be estimated for each independent event. Then, step (2) of the analysis can be carried out, which consists of checking the mutual independence of $S, V$ and $D$. This check is necessary to provide further support to the assumption of independence among the identified rainfall events. In fact, independent events are characterised by the absence of temporal correlation for each of the stochastic processes $S, V$ and $D$, as well the absence of mutual correlation between $S, V$ and $S, D$. Besides, independence among $S, V$ and $D$ allows us to introduce simplifying assumptions for the analytical model of the number and volume of tank overflows (see Sect. 4.1).

The dependence structure was analysed by estimating the linear autocorrelation coefficient, for increasing lags up to 10 , of each stochastic process and the cross correlation coefficient, at lag 0 , among them. The obtained coefficients were compared against Anderson limits of the null value at the $98 \%$ confidence level.

Finally, step (3) of the analysis can be carried out by fitting pdfs to the stochastic processes $V$ and $D$. Different candidate models were considered, namely, the exponential distribution, which is traditionally chosen in many studies, as 
well as the Weibull, Gamma-2, Lognormal and generalised Pareto distributions. This latter distribution turned out to be the most appropriate for $v(t)$ in the case studies considered here (see Sects 4.1 and 4.2). In fact, this choice is supported by the maximum entropy principle applied to hydrological variables, which implies that the appropriate distribution of certain variables, for a given coefficient of variation, should lead to the maximum entropy. The physical reason for this outcome would be that "nature behaves in a manner that makes uncertainty as high as possible" (Koutsoyiannis, 2005). The cumulative probability function for the generalised Pareto distribution is given by

$F_{V}(v)=1-(1+\kappa v / \alpha)^{-1 / \kappa}$,

where $\kappa>0$ and $\alpha>0$ are the shape and scale parameters, respectively. The generalised Pareto distribution performed satisfactorily for $d$ as well, although for Valencia the Gamma-2 model provided a slightly better fit (see Sects. 4.1 and 4.2).

The above theoretical framework works under the assumption that rainfall descriptors are not affected by seasonality. However, seasonality could indeed play an important role with regard to pollutants build-up and wash-off processes. Therefore, the results for the case study are also computed by taking seasonality into consideration, to check its actual significance (see Sect. 4.3).

\subsection{Rainfall-runoff model}

An aggregated event rainfall-runoff model was used in order to estimate the volume of sewer discharge generated in the catchment by each rainfall event. The SCS-CN model was adopted, which was previously recalibrated for the urban area of Valencia (González, 2001). Model basis is the continuity equation

$v=r(v)+f(v)+P_{0}$,

where $P_{0}$ is the initial abstraction and $v, r(v)$ and $f(v)$ are volumes of rainfall, runoff and infiltration of the event, respectively. According to the SCS-CN model $r(v)$ is given by

$$
\begin{cases}r(v)=0 & \text { if } v \leq P_{0} \\ r(v)=\frac{\left(v-P_{0}\right)^{2}}{v+4 P_{0}} & \text { if } v>P_{0}\end{cases}
$$

Equation (5) implies that no runoff occurs when event rainfall depth is smaller than the threshold value $P_{0}$. Thus, under the assumption that $V$ is distributed according to the generalised Pareto probability distribution, we obtained that the cumulative probability of null flow is given by

$F_{R}(0)=F_{V}\left(P_{0}\right)=\int_{0}^{P_{0}} f_{V}(v) d v=1-\left(1+\kappa P_{0} / \alpha\right)^{-1 / \kappa}$

In (6), $R$ indicates the random variable whose outcome is the event runoff $r$. On the other hand, when the threshold value $P_{0}$ is exceeded then $R>0$, and the expression for the cumulative probability distribution of runoff volume is

$$
\begin{aligned}
F_{R}(r) & =\int_{0}^{r} f_{R}(r) d r=F_{R}(0)+\int_{P_{0}}^{v} f_{V}(v) d v \\
& =1-(1+\kappa v / \alpha)^{-1 / \kappa}
\end{aligned}
$$

with an implicit expression for $v(r)$. Thus, the probability density function for runoff volume is given by

$$
\begin{aligned}
f_{R}(r) & =\frac{d}{d r} F_{R}(r)=\frac{1}{\alpha}\left(1+\kappa \frac{v}{\alpha}\right)^{-1-1 / \kappa} \cdot \frac{d v}{d r} \\
& =\frac{\frac{1}{\alpha}\left(1+\kappa \frac{v}{\alpha}\right)^{-1-1 / \kappa}}{\frac{d}{d v} r(v)}
\end{aligned}
$$

with again an implicit expression for $v(r)$.

Total area $A$ of the urban catchment was divided into 4 different types of land use, each one affected by a different initial abstraction $P_{0 i}$. Considering the catchment size (68.8 ha) and shape for the case study considered here the assumption of spatial uniform rainfall appears to be reasonable. Thus, the runoff volume generated by the rainfall event is:

$r(v)=\sum_{i=1}^{4} a_{i} r^{(i)}(v)$

where $a_{i}$ is the land use area ratio defined by (1) and $r^{(i)}(v)$ is the runoff generated in area $A_{i}$ computed by applying (5) to area $i$. Therefore, Eq. (8) can be rewritten as

$$
\begin{aligned}
f_{R}(r) & =\frac{d}{d r} F_{R}(r)=\frac{1}{\alpha}\left(1+\kappa \frac{v}{\alpha}\right)^{-1-1 / \kappa} \cdot \frac{d v}{d r} \\
& =\frac{\frac{1}{\alpha}\left(1+\kappa \frac{v}{\alpha}\right)^{-1-1 / \kappa}}{\sum_{i=1}^{4} a_{i} \frac{d}{d v} r^{(i)}(v)} .
\end{aligned}
$$

According to the minimum initial abstraction $P_{01}$ which corresponds to paved areas (see Table 1), the impulse probability for $r=0$ is

$F_{R}(0)=F_{V}\left(P_{01}\right)=\int_{v=0}^{P_{01}} f_{V}(v) d v=1-\left(1+\kappa \frac{P_{01}}{\alpha}\right)^{-1 / \kappa}$.

Finally, taking into account Eq. (10) and the impulse probability at $r=0$, the expected value of event runoff volume in the catchment takes the form

$$
E(R)=\int_{0}^{\infty} r f_{R}(r) d r=\frac{1}{\alpha} \int_{0}^{\infty}\left(1+\kappa \frac{v}{\alpha}\right)^{-1-1 / \kappa} \sum_{i=1}^{4} a_{i} r^{(i)}(v) d v .
$$

\subsection{Tank overflow model}

The purpose of tank overflow model is to provide an analytical relationship for the number and volume of overflows from a CSO system controlled by a tank with volume $V_{D}$. We indicate with the symbol $Q_{V}$ the maximum flow rate from the tank to the waste water treatment plant (WWTP) (see Fig. 3). 

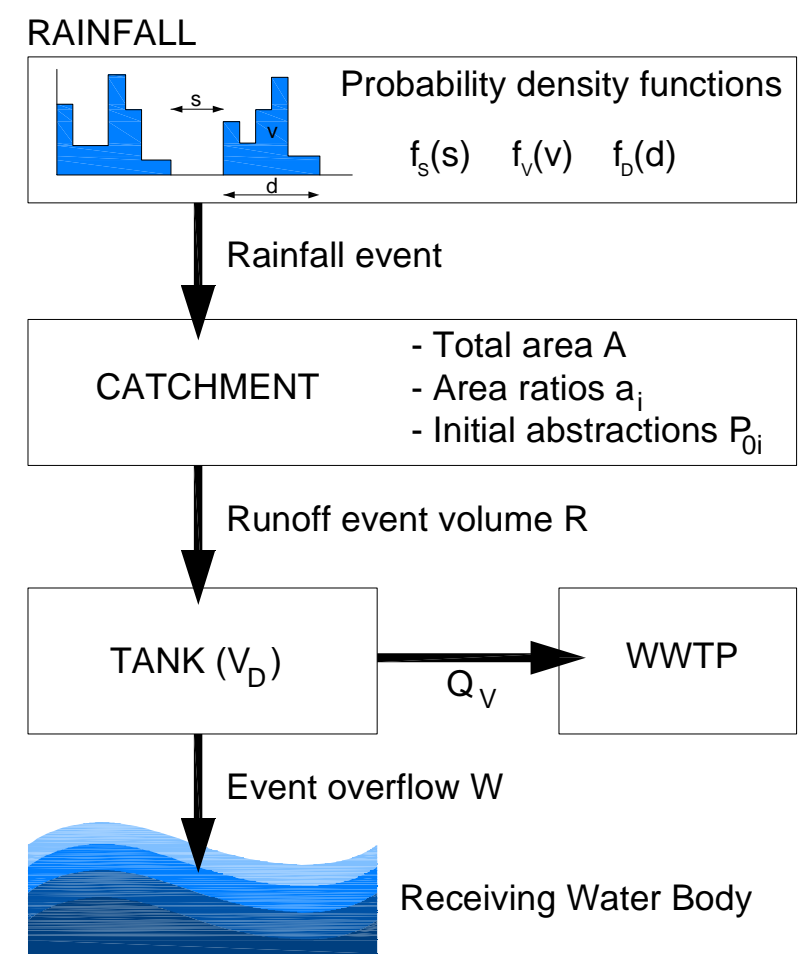

Fig. 3. System elements: rainfall, runoff and detention.

To derive the above analytical expression, we need to first deduce the probability density function of the overflow volume which we assumed to be a random variable that will be indicated with the symbol $W$. Let us assume that runoff occurs as a rectangular pulse. Then, overflow volume during an assigned event is given by

$\left\{\begin{array}{l}w=0 \\ \text { if } r(v) \leq V_{D}+Q_{V} \cdot\left(d(t)+t_{C}-t_{R}\right) \\ w=r(v)-V_{D}-Q_{V} \cdot\left(d(t)+t_{C}-t_{R}\right) \\ \text { if } r(v)>V_{D}+Q_{V} \cdot\left(d(t)+t_{C}-t_{R}\right)\end{array}\right.$

where $d(t)$ is duration of rainfall event, $t_{C}$ is concentration time of the catchment and $t_{R}$ is lag time between storm and runoff origins. In order to obtain a precautionary estimation, we set $Q_{V}=0$ during the event, so that the event duration $d$ does not play any role in the derivation of the tank efficiencies (see Eqs. 20 and 21). Therefore the probability of no overflow is given by

$F_{W}(0)=F_{R}\left(V_{D}\right)$,

and the runoff volume $r$ is determined by event rainfall depth only, which we assumed to be distributed according to a generalised Pareto distribution (see Sect. 3.1). Given that $Q_{V}=0$, it follows that

$$
\begin{aligned}
F_{W}(0) & =F_{R}\left(V_{D}\right)=F_{V}\left(V_{D}^{*}\right)=1-\left(1+\kappa V_{D}^{*} / \alpha\right)^{-1 / \kappa} \\
w & =0 \Leftrightarrow v \leq V_{D}^{*}
\end{aligned}
$$

where $V_{D}^{*}$ is the rainfall depth generating a runoff volume equal to the tank volume, that is, $r\left(V_{D}^{*}\right)=V_{D}$. Thus, if rainfall volume is smaller or equal than this threshold value, that is, if $\mathrm{v} \leq \mathrm{V}_{D}^{*}$, then there is no overflow $(w=0)$. If $v>V_{D}^{*}$, then $w>0$ and therefore,

$$
\begin{gathered}
F_{W}(w)-F_{W}(0)=F_{R}(r)-F_{R}\left(V_{D}\right)=\int_{V_{D}}^{r} f_{R}(r) d r \\
w>0 \Leftrightarrow v>V_{D}^{*} .
\end{gathered}
$$

By considering that $F_{R}(r)=F_{V}(v)$ and $F_{R}\left(V_{D}\right)=F_{V}\left(V_{D} *\right)$, the latter probability can be written as

$$
\begin{aligned}
F_{W}(w)-F_{W}(0) & =F_{V}(v)-F_{V}\left(V_{D^{*}}\right)=\int_{V_{D}^{*}}^{v} f_{V}(v) d v \\
& =\left(1+\kappa V_{D}^{*} / \alpha\right)^{-1 / \kappa}-(1+\kappa v / \alpha)^{-1 / \kappa} .
\end{aligned}
$$

Then, the distribution function assumes the following expression:

$F_{W}(w)= \begin{cases}1-\left(1+\kappa V_{D}^{*} / \alpha\right)^{-1 / \kappa} & \text { if } w=0 \\ 1-(1+\kappa v / \alpha)^{-1 / \kappa} & \text { if } w>0 .\end{cases}$

Therefore, the expected value of the spilled volume can be derived, given by the relationship

$E(W)=\frac{1}{\alpha} \int_{V_{D}^{*}}^{\infty}\left(\sum_{i=1}^{N} a_{i} r^{(i)}(v)-V_{D}\right)\left(1+\kappa \frac{v}{\alpha}\right)^{-1-1 / \kappa} d v$.

From Eqs. (12) and (19) volumetric efficiency of the tank, $\mu_{v}\left(V_{D}\right)$, can be derived, that is,

$\mu_{v}\left(V_{D}\right)=1-\frac{E(W)}{E(R)}=1-\frac{\int_{V_{D}^{*}}^{\infty}\left(\sum_{i=1}^{N} a_{i} r^{(i)}(v)-V_{D}\right)\left(1+\kappa \frac{v}{\alpha}\right)^{-1-1 / \kappa} d v}{\int_{0}^{\infty} \sum_{i=1}^{N} a_{i} r^{(i)}(v)\left(1+\kappa \frac{v}{\alpha}\right)^{-1-1 / \kappa} d v}$.

The volumetric efficiency is an important index of performance, allowing to assess the mean volume detained by the tank expressed as fraction of event runoff.

Finally, the overflow reduction efficiency, $\mu_{o}\left(V_{D}\right)$, can be derived from Eq. (15) as it states the probability of no overflow. It is expressed by the relationship

$\mu_{o}\left(V_{D}\right)=F_{W}(0)=1-\left(1+\kappa V_{D}^{*} / \alpha\right)^{-1 / \kappa}$

and gives the probability of an event not to produce overflow as a function of detention tank volume.

\section{Results}

\subsection{Rainfall data analysis for Valencia}

Different trial values of $s_{\text {crit }}$ were considered in the range between $5 \mathrm{~min}$ (the temporal resolution of the available data record) and $48 \mathrm{~h}$. For each selected value of $s_{\text {crit }}$ the resulting $s$ series was extracted and maximum likelihood estimates for the $\beta$ parameter were obtained. Besides, for each case, 


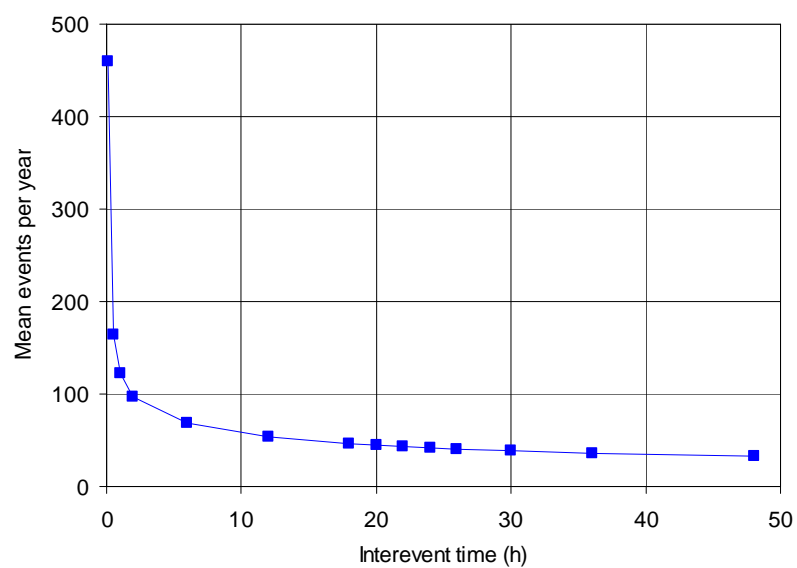

(a)

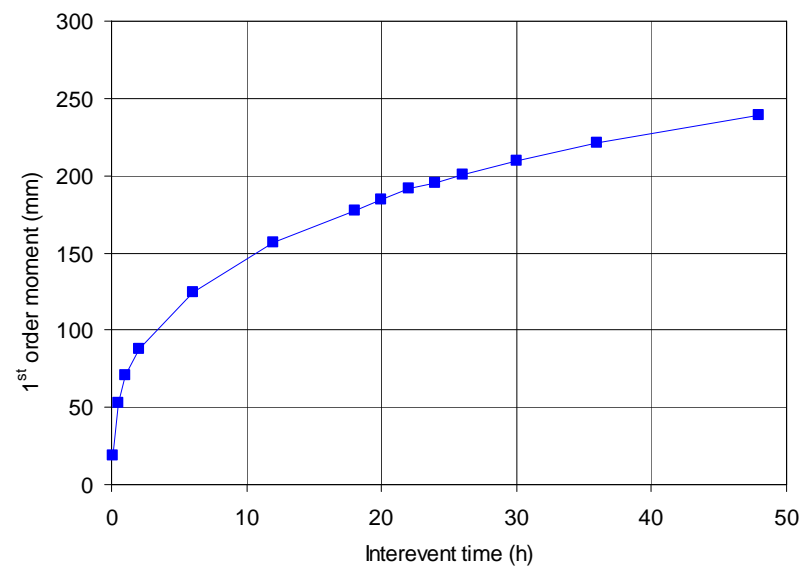

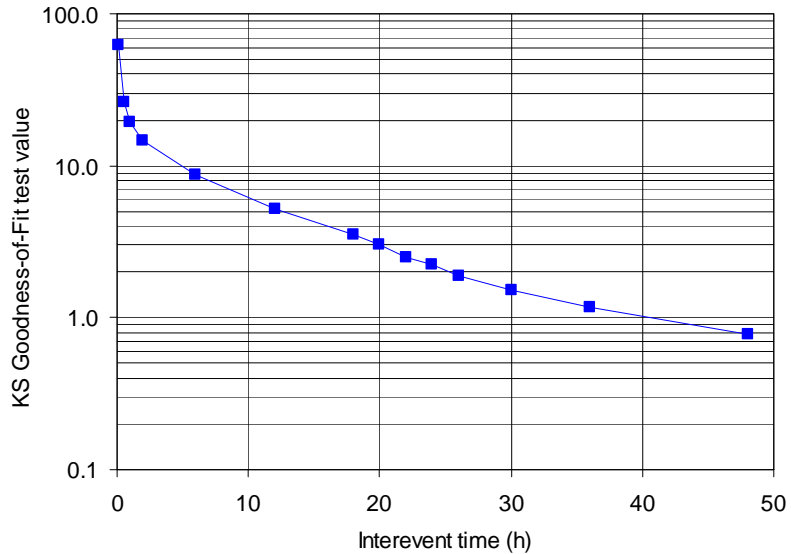

(b)

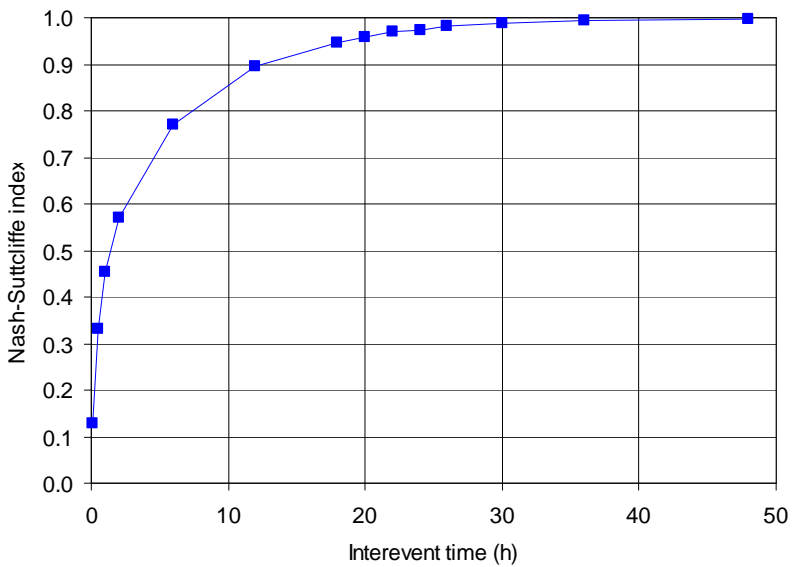

(c)

Fig. 4. Decision parameter evolution for critical interevent time selection. the statistical tests mentioned in Sect. 3.1 were performed. The results are summarized in Fig. 4. Notice that, according to the tests, $s_{\text {crit }}$ seems to vary in the range between 18 and $30 \mathrm{~h}$. Relationships of the average number of events per year and the mean value of $S$ against $s_{\text {crit }}$, begin to exhibit linearity from an $s_{\text {crit }}$ of $18-20 \mathrm{~h}$. The NS index is above 0.95 for an $s_{\text {crit }}$ greater than $18 \mathrm{~h}$. Finally, the KS test is satisfactory for an $s_{\text {crit }}$ value around $30 \mathrm{~h}$ (the $p$-value is 1.308 for a significance level $\alpha=0.01$ ). Thus, a value of $22 \mathrm{~h}$, which corresponds to $\beta=0.0059 \mathrm{~h}^{-1}$, was finally selected. It is close to the lower bound of the plausible values in order to increase the sample size of the rainfall events. Given that $s_{\text {crit }}$ is well greater than $1 \mathrm{~h}$ (the same result is obtained for Santander, see Sect. 4.2) it turns out that the time resolution of the rainfall record is fine enough to effectively describe the temporal dynamics of rainfall events.

The selection of the optimal value of $s_{\text {crit }}$ is also supported by the correlation analysis. In fact, it can be proved that the autocorrelation coefficients, $\rho_{V}(k)$ and $\rho_{D}(k)$, for event rainfall depth and event duration are always included within the $98 \%$ confidence limits for null value. For cross correlation analysis, cross correlations coefficients between $s, v$ and $s, d$ are close to $0\left(\rho_{S, V}(0)=-0.01\right.$ and $\left.\rho_{S, D}(0)=-0.03\right)$ and so included within the same confidence limits. Figure 5 shows scatterplots of $v$ versus $d$ and $s$. Notice that mutual independence between $v$ and $s$ is confirmed while one notes the presence of correlation between $v$ and $d\left(\rho_{V, D}(0)=0.667\right)$. This outcome was also found by other authors (Adams and Papa, 2000). However, the above cross correlation is not appreciable enough to affect the probabilistic analysis later developed on Sect. 4.3, also because event duration is finally not affecting the results (see Eqs. 20 and 21).

Table 2 shows the $\mathrm{CV}$ and $\gamma$ values for the $v(t)$ and $d(t)$ time series. These values were also computed by censoring events whose rainfall depth is lower than $1 \mathrm{~mm}$. Results show that the exponential model is quite unlikely in all cases, because CV and $\gamma$ are not close to target values of 1 and 2 , respectively, with the sole exception of the $\mathrm{CV}$ value for censored $d(t)$ series. Therefore a different pdf has to be selected for event rainfall depth and event duration. Competing formulations were identified by taking into account that the identified series are characterised by high skewness. Accordingly, Weibull, Gamma-2, Lognormal and Pareto distributions were considered by estimating their parameters with the 


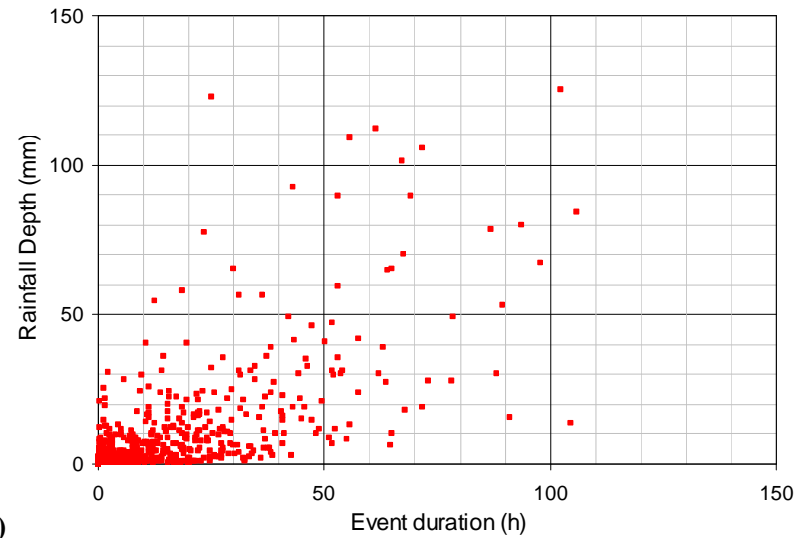

(a)

Event duration (h)

(b)

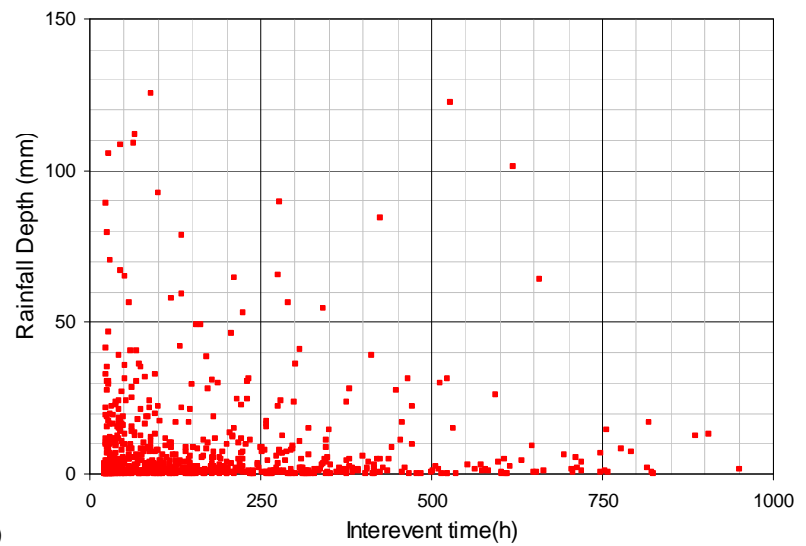

Fig. 5. Scatterplots of $v$ versus $d$ (left) and $s$ (right).

Table 2. Sample coefficients of variation (CV) and skewness $(\gamma)$ of event rainfall depth and duration estimated for the Valencia raingauge.

\begin{tabular}{lcccc}
\hline & \multicolumn{2}{c}{ Non censored series } & \multicolumn{2}{c}{ Censored series $(1 \mathrm{~mm})$} \\
& $\mathrm{CV}$ & $\gamma$ & $\mathrm{CV}$ & $\gamma$ \\
\hline Depth & 2.06 & 4.76 & 1.57 & 3.97 \\
Duration & 1.47 & 2.80 & 1.14 & 2.32 \\
\hline
\end{tabular}

maximum likelihood procedure (MLE) and graphically compared against the empirical distribution (see Fig. 6). Moreover, goodness-of-fit testing was performed by KolmogorovSmirnov (KS) test for exponential distribution, and Cramervon-Mises (CVM) test (Choulakian and Stephens, 2001) for Pareto and Gamma-2 distributions. It turns out that, for the selected distributions, fit improves significantly if censored series are used, as summarized in Table 3. It turns out that $v(t)$ is better described by the Pareto model, while the Gamma-2 model provides the better fit for $d(t)$, even though fitting provided by the exponential model is not much different in this latter case (see Fig. 6). Parameter values for best distributions are summarized in Table 4.

In order to take seasonaolity into account the same analysis is carried out separately for the four seasons. The results (not shown) indicate that the Pareto model is still outperforming the exponential one. The seasonal rainfall model will be used to compute tank efficiencies for each season (see Sect. 4.3).

Other models than the exponential one for event rainfall depths were employed by other authors. For instance, the Weibull model turned out to be more appropriate for some locations (Brescia, Milano, Palermo, Parma and Pavia) in Italy (Balistrocchi et al., 2008).

\subsection{Rainfall data analysis for Santander}

Rainfall analysis was repeated for the Santander rainfall series. In this case, a $s_{\text {crit }}=12 \mathrm{~h}$ was obtained. As for the Valencia case study, $v(t)$ is well described by the Pareto distribution (see Table 5), which turns out to be the best model for $d(t)$ also. The fit provided by the exponential model is again significantly outperformed by the Pareto alternative (see Fig. 7).

It is interesting to compare the results obtained for Valencia and Santander, which are characterised by a semiarid and humid climate, respectively. The critical interevent time is half at Santander compared to that at Valencia, highlighting that for a maritime climate storms occur more frequently (Table 6). An important difference lies in the event duration pdf. While at Valencia the Gamma-2 probability function provides good fit (being very close to the exponential model), the Pareto model provides a better fit at Santander as expected for a more heavy-tailed behaviour. These results confirm the significant variability of statistical behaviours regarding the rainfall regime and justify the effort undertaken in this paper to develop a flexible approach to identify the most appropriate probability distributions for rainfall descriptors.

\subsection{Application of the probabilistic model for detention tank design}

The analytical model is finally applied to the selected case study of the Pio XII urban drainage catchment in Valencia. According to catchment land use (see Table 1) and estimated rainfall descriptors (see Table 4), expected values for runoff volume, $E(R)$, and overflow volume, $E(W)$, are obtained for different trial values of tank volume $V_{D}$. The above expected values have been estimated by means of numerical integration of $F_{R}(r)$ and $F_{W}(w)$. Thus, the tank efficiencies $\mu_{v}\left(V_{D}\right)$ and $\mu_{o}\left(V_{D}\right)$ were evaluated through Eqs. (20) and (21). 
Table 3. Goodness of fit statistic values ( $p$-value) for original and censored rainfall series.

\begin{tabular}{lcccc}
\hline Rainfall descriptor & Probability & \multicolumn{3}{c}{ Goodness of fit test } \\
\cline { 3 - 5 } & distribution function & Test & Series & test statistic value \\
\hline Event rainfall depth & Pareto & CVM & Original & 0.76 \\
& & CVM & Censored & $\mathbf{0 . 6 2}$ \\
Gamma-2 & CVM & Original & 1.01 \\
& & CVM & Censored & $\mathbf{0 . 1 1}$ \\
& \multirow{2}{*}{ Exponential duration } & KS & Original & 6.93 \\
& & KS & Censored & $\mathbf{2 . 3 9}$ \\
\hline
\end{tabular}

Table 4. Distribution functions and related MLE parameters for rainfall descriptors related to Valencia raingauge. Rainfall series was censored by excluding events whose rainfall depth is lower than $1 \mathrm{~mm} . F$ and $f$ indicate cumulative probability and the probability density, respectively. Note that an explicit formulation of $F$ can not be provided for the Gamma-2 distribution.

\begin{tabular}{llll}
\hline Rainfall descriptor & & Probability function & MLE Parameters \\
\hline Interevent time & Exponential & $F_{S}(s)=1-e^{-\beta\left(s-s_{\text {crit }}\right)}$ & $\begin{array}{l}\beta=0.0059 \\
s_{\text {crit }}=22 \mathrm{~h}\end{array}$ \\
& & & $\kappa=0.4110$ \\
Event rainfall depth & Pareto & $F_{V}(v)=1-\left(1+\kappa \frac{v}{\alpha}\right)^{-1 / \kappa}$ & $\begin{array}{l}\kappa=8.4605 \\
\end{array}$ \\
& Gamma-2 & $f_{D}(d)=\frac{\lambda^{\varepsilon}}{\Gamma(\varepsilon)} d^{\varepsilon-1} e^{-\lambda d}$ & $\begin{array}{l}\varepsilon=0.7401 \\
\text { Event duration }\end{array}$ \\
& & & $\lambda=0.0364$ \\
& Exponential & $F_{D}(d)=1-e^{-\lambda d}$ & $\lambda=0.0492$ \\
\hline
\end{tabular}

Table 5. Distribution functions and related MLE parameters for rainfall descriptors estimated for Santander raingauge.

\begin{tabular}{lcll}
\hline Variable & & Probability function & MLE Parameters \\
\hline Interevent time & Exponential & $F_{S}(s)=1-e^{-\beta\left(s-s_{\text {crit }}\right)}$ & $\begin{array}{l}\beta=0.0158 \\
s_{\text {crit }}=12 \mathrm{~h}\end{array}$ \\
& & & \\
Event rainfall depth & Pareto & $F_{V}(v)=1-\left(1+\kappa \frac{v}{\alpha}\right)^{-1 / \kappa}$ & $\begin{array}{l}\kappa=0.3435 \\
\alpha=9.7431\end{array}$ \\
& & & \\
Event duration & Pareto & $F_{D}(d)=1-\left(1-\frac{\gamma d}{\mu}\right)^{-1 / \gamma}$ & $\begin{array}{l}\gamma=0.1000 \\
\mu=25.4573\end{array}$ \\
\hline
\end{tabular}

Table 6. Comparison between Valencia (VLC) and Santander (STD) rainfall descriptors.

\begin{tabular}{lcccccccc}
\hline Rain- & Critical IET & E(S) & Average & \multicolumn{2}{c}{ Rainfall depth } & \multicolumn{2}{c}{ Duration } \\
\cline { 5 - 8 } gauge & $(\mathrm{h})$ & $(\mathrm{h})$ & $\begin{array}{c}\text { number of } \\
\text { events per year }\end{array}$ & PDF & $\begin{array}{c}\mathrm{E}(\mathrm{V}) \\
(\mathrm{mm})\end{array}$ & PDF & $\begin{array}{c}\text { E(D) } \\
\text { (h) }\end{array}$ \\
\hline VLC & 22 & 191 & 27.3 & Pareto & 14.4 & Gamma-2 & 20.3 \\
STD & 12 & 75 & 68.9 & Pareto & 14.8 & Pareto & 28.3 \\
\hline
\end{tabular}




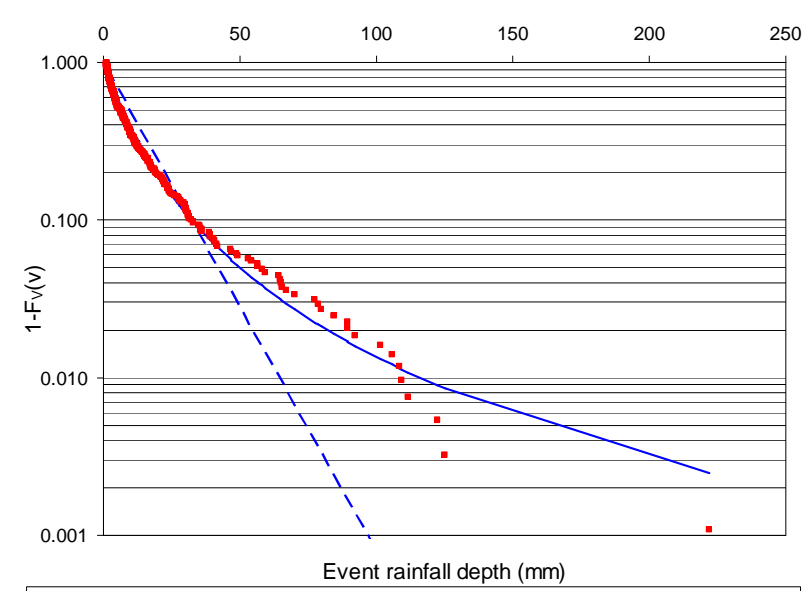

(a) - OBSERVED DATA — FITTED PARETO - - FITTED EXPONENTIAL

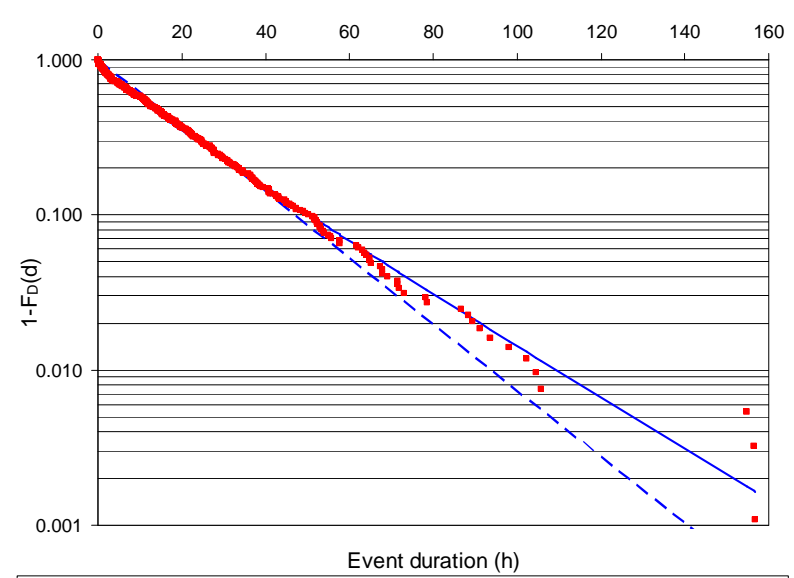

(b) - OBSERVED DATA — FITTED GAMMA-2 - - FITTED EXPONENTIAL

Fig. 6. Exponential and alternative probability distributions for rainfall event depth and duration (Valencia raingauge).
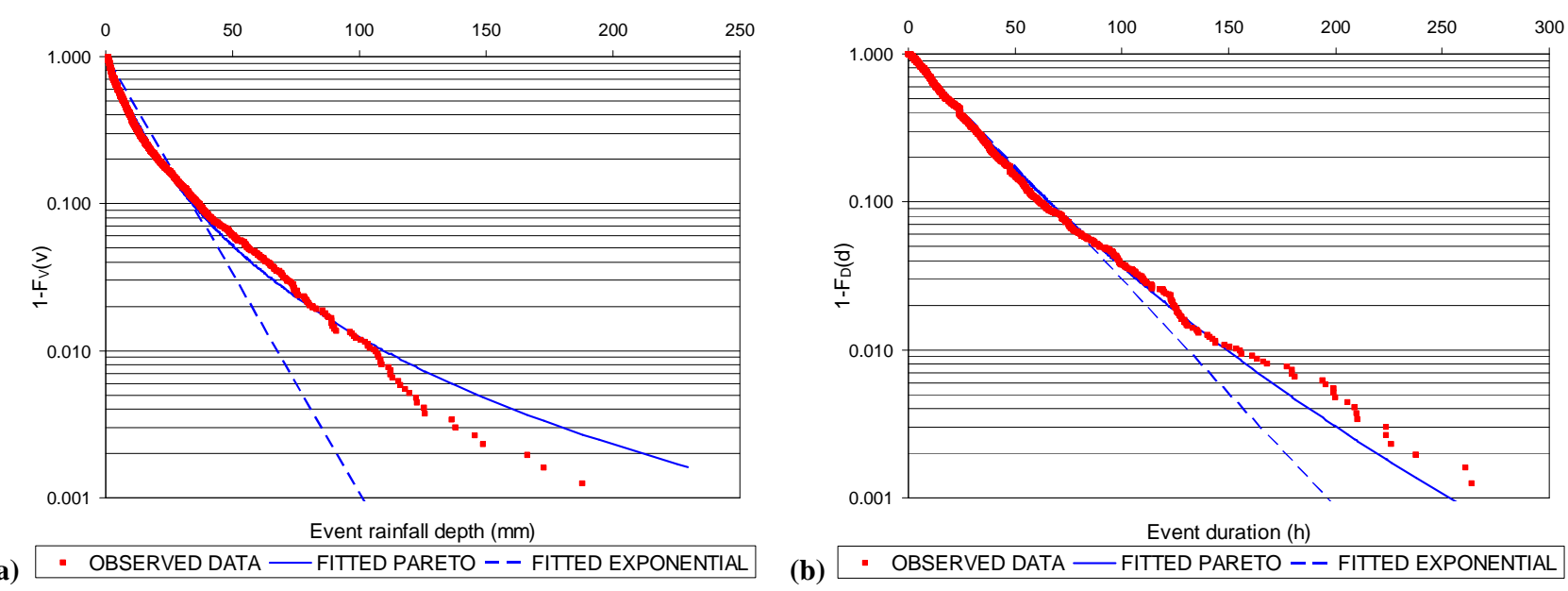

Fig. 7. Exponential and alternative probability distributions for rainfall event depth and duration (Santander raingauge).

In order to validate the results given by the analytical method, a continuous simulation was performed by using the observed 17-year rainfall record which includes a total of 464 independent rainfall events (identified by adopting $s_{\text {crit }}=$ $22 \mathrm{~h}$ ). A complete model of the sewer network was built with InfoWorks CS software (Wallingford Software, 2008). The model describes the whole sewer network over the catchment with 565 nodes and 562 pipes, by adopting a number of subcatchments equal to the number of nodes. Infiltration parameters of the SCS-CN model were previously calibrated as referred in Sect. 3.2. With regard to numerical calculations, the implicit Preissmann scheme is used, with a minimum $60 \mathrm{~s}$ time step. Simulations were thus performed for a set of 7 tank volumes defined by specific volumes equal to $5,10,36$, $50,75,100$ and $200 \mathrm{~m}^{3} / \mathrm{ha}$. The value $36 \mathrm{~m}^{3} / \mathrm{ha}$ was simulated because it corresponds with the specific volume traditionnally recommended by the Municipality of Valencia.
For each tank volume, $V_{D}$, total volume spilled per event $w_{j}$ was obtained. Depending on total runoff volume per event, $r_{j}$, volumetric efficiencies are evaluated by

$\mu_{v, \operatorname{sim}}=1-\frac{\sum_{j=1}^{464} w_{j}}{\sum_{j=1}^{464} r_{j}}$.

Similarly, the number of simulations generating overflow were counted to evaluate the overflow reduction efficiency,

$\mu_{o, \operatorname{sim}}=1-\frac{\sum_{j=1}^{464} \delta_{j}}{464}$ 

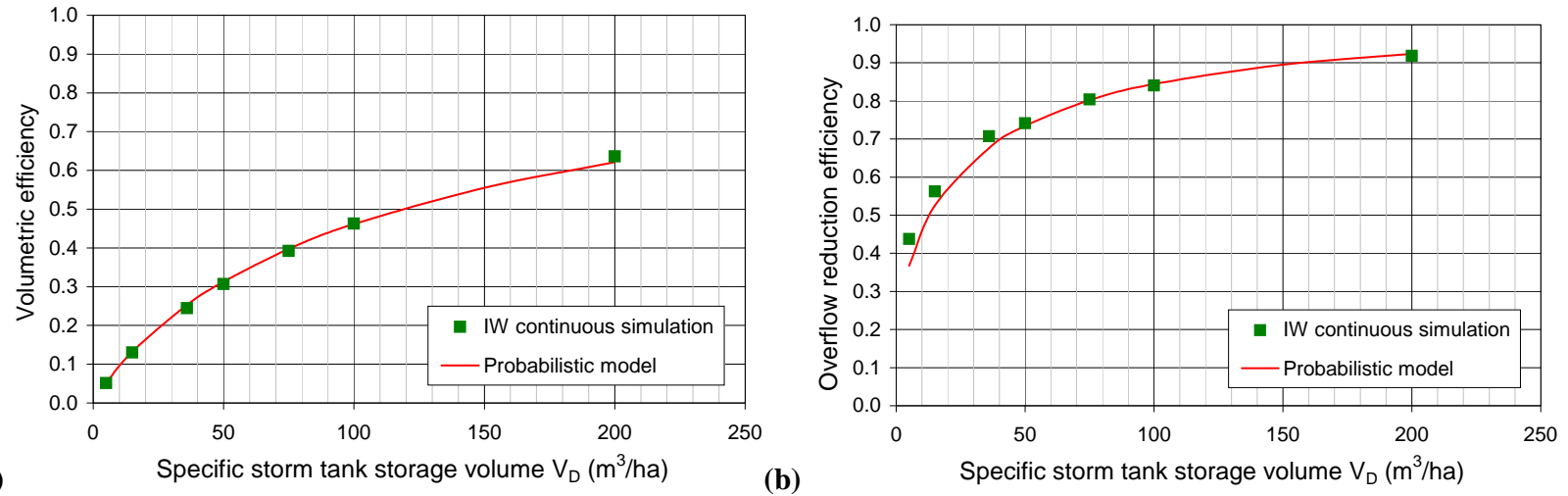

(a)

Fig. 8. Comparison between probabilistic model and continuous simulation results.

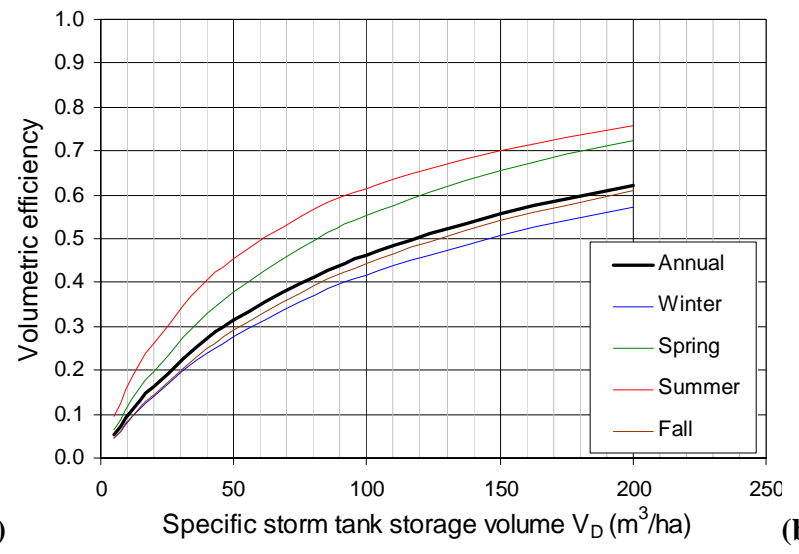

(b)

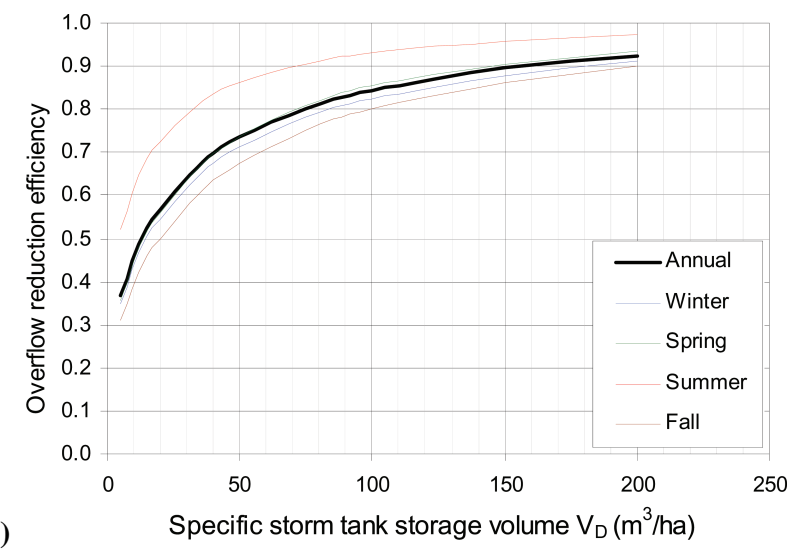

Fig. 9. Comparison between annual and seasonal results for the analytical model.

where

$\delta_{j}=\left\{\begin{array}{l}1 \text { if } w_{j}>0 \\ 0 \text { if } w_{j}=0 .\end{array}\right.$

Figure 8 summarizes volumetric efficiencies and overflow reduction efficiencies obtained with both the probabilistic and the continuous approaches. It can be seen that the probabilistic model provided satisfactory results. In particular, the specific volume recommended by the Municipality of Valencia allows to reach an overflow reduction efficiency of $70 \%$. However, this corresponds to a poor volumetric efficiency of $20 \%$. This latter value could be improved by considering a flow rate to the WWTP $\left(Q_{V}>0\right)$.

Finally, tank performances are recalculated taken seasonality into account for the series of Valencia (Fig. 9). For each season, a volumetric and overflow reduction efficiency curve is obtained and compared with respect to those previously obtained. One can see that the effect of seasonality is indeed noticeable, but the essence of the results is unchanged. In fact one can see that the seasonal growth curves of volumetric efficiency and overflow reduction efficiency against the return period have basically similar shapes, with maximum efficiency in Summer and minimum efficiency during Fall and Winter, as expected.

\section{Conclusions}

Exponential models have been widely and successfully used in the US and Canada for rainfall regime characterization as a preliminary step for the development of detention tank design procedures. Nevertheless, case studies prove that such a modelling solution is simpler but often inefficient in many locations, including Valencia and Santander, considered in this study. As expected according to entropy based considerations, the Pareto probability distribution provided a better fit for event rainfall depth, while event duration is better fitted by the Gamma-2 and Pareto distributions at Valencia and Santander, respectively. These facts highlight the importance of local conditions for this issue.

An analytical approach was proposed to assess long term volumetric and overflow reduction efficiencies of storm detention tanks for sewer systems. Application of these 
probabilistic expressions at an urban catchment in Valencia shows satisfactory performance for a simple single tank system. Results presented here provide support to the design of storm detention tanks for limiting pollutant concentration into receiving water bodies.

Edited by: D. Koutsoyiannis

\section{References}

Adams, B. J., Fraser, H. G., Howard, C. D. D., and Hanafy, M. S.: Meteorological data analysis for drainage system design, J. Environ. Eng.-ASCE, 112(5), 824-847, 1986.

Adams, B. J. and Papa F.: Urban stormwater management planning with analytical probabilistic methods, John Wiley \& Sons, Inc, New York, USA, 358 pp., 2000.

Balistrocchi, M., Grossi, G., and Bacchi, B.: Assessment of the long term efficiency of CSO capture tanks by semiprobabilistic methods. Proceedings of the 11th International Conference on Urban Drainage, Edinburg, Scotland, UK, 1-5 September, 2008.

Bonta, J. V. and Rao, R.: Factors affecting the identification of independent storm events, J. Hydrol., 98(3-4), 275-293, 1988.

Calabro, P. S.: Design storms and water quality control, J. Hydrol. Eng., 9(1), 28-34, 2004.

Choulakian, V. and Stephens, M. A.: Goodness-of-fit tests for the generalized Pareto distribution, Technometrics, 43(4), 478-484, 2001.

Cox, D. and Isham, V.: Point Processes, 1st edn., Chapman and Hall, London, England, 188 pp., 1980.

Deutsch, J-C., Revitt, M., Ellis B., and Scholes, L.: Review of the use of stormwater BMPs in Europe. Project EU RTD 5th Framework Prog, DayWater Research Project, Middlesex University, 2003.

Di Toro, D. M. and Small, M. J.: Stormwater interception and storage, J. Environ. Eng.- ASCE, 105(EE1), 43-54, 1979.

Driscoll, E. D., Di Toro, D. M., and Gaboury, D.: Methodology for analysis for detention basins for control or urban runoff quality, EPA 440/5-87-001, US Environmental Protection Agency, Office of Water, Nonpoint Source Branch, Washington, DC, USA, 1986.
González, J.: Metodología para la modelación y diseño de redes de saneamiento urbano aplicada a la ciudad de Valencia. Technical dissertation, Universidad Politécnica de Valencia, Valencia, 2001.

Guo, Y. and Adams, B. J.: Analysis of detention ponds for storm water quality control, Water Resour. Res., 35(8), 2447-2456, 1999.

Guo, J. C. Y. and Urbonas, B.: Runoff capture and delivery curves for storm-water quality control designs, J. Water Res. Pl. ASCE, 128(3), 208-215, 2002.

Koutsoyiannis, D. and Xanthopoulos, A.: A dynamic model for short-scale rainfall disaggregation, Hydrol. Sci. J., 35(3) 303322, 1990.

Koutsoyiannis, D.: Uncertainty, entropy, scaling and hydrological stochastics. 1. Marginal distributional properties of hydrological processes and state scaling, Hydrol. Sci. J., 50(3), 381-404, 2005.

Law, A. M. and Kelton, W. D.: Simulation, modeling and analysis, 2nd edn., McGraw Hill, Inc, New York, USA, 759 pp., 1991.

Municipality of Valencia: Normativa para obras de saneamiento de la ciudad de Valencia Servicio del Ciclo Integral del Agua, 2004.

Papa, F. and Adams, B. J.: Application of derived probability and dynamic programming techniques to planning regional stormwater management systems, Water Sci. Technol., 36(5), 227-234, 1996.

Restrepo-Posada, P. J. and Eagleson, P. S.: Identification of independent rainstorms, J. Hydrol., 55(1-4), 303-319, 1982.

Wallingford Software Ltd.: Infoworks CS (Collection Systems) version 8.5.0. Desktop Help, 2008.

Walker, D., Golden, J., Bingham, D. and Driscoll, E. D.: Combined Sewer Overflow Control. EPA 625/R-93-007, US Environmental Protection Agency, Office of Research and Development, Center of Environmental Research Information, Cincinnati, Ohio, 1993.

Woods-Ballard, B., Kellagher, R., Martin, P., Jefferies, C., Bray, R., and Shaffer, P.: The SUDS Manual, CIRIA C697, London, UK, 2007. 